\title{
Apoptotic cell clearance and its role in the origin and resolution of chronic inflammation
}

\section{Luis Enrique Muñoz ${ }^{1}$, Christian Berens ${ }^{2}$, Kirsten Lauber ${ }^{3}$, Udo S. Gaipl ${ }^{4}$ and Martin Herrmann ${ }^{1}$}

\author{
' Department of Internal Medicine 3, Rheumatology and Immunology, Friedrich-Alexander University of Erlangen-Nürnberg, Erlangen, Germany \\ 2 Institute of Molecular Pathogenesis, Friedrich-Loeffler-Institut, Federal Research Institute for Animal Health, Jena, Germany \\ ${ }^{3}$ Department of Radiation Oncology, Ludwig-Maximilians-University Munich, Munich, Germany \\ ${ }^{4}$ Department of Radiation Oncology, University Hospital Erlangen, Friedrich-Alexander University of Erlangen-Nürnberg, Erlangen, Germany \\ ${ }^{*}$ Correspondence: luis.munoz@uk-erlangen.de
}

Edited and reviewed by:

Pietro Ghezzi, Brighton and Sussex Medical School, UK

Keywords: clearance, cell death, phagocytosis, chronic, inflammation, cancer, atherosclerosis, autoimmunity

During normal tissue turnover, innate immune sentinels swiftly clear dying cells in an immunologically silent manner. Large amounts of nuclear chromatin are meticulously kept away from the immune system to prevent inflammation and, eventually, autoimmunity from developing. In case this highly efficient surveillance system is derailed, the unanticipated presence of postmortem remnants in tissues can challenge the otherwise normally ensuing immunological tolerance. Apoptotic cell death is the most natural way to preserve this precious tissue homeostasis. Early recognition and swift clearance of cells undergoing apoptosis ensures the prevention of tissue damage and autoimmune reactions (1). Kimani et al. thoroughly review in this Research Topic, the most recent evidence linking autoimmune diseases and the recognition of apoptotic cells via surface-exposed phosphatidylserine (2).

Besides the autoimmune phenotype of chronic inflammatory rheumatoid disorders, a plethora of pathologies have been associated with defects in genes involved in the clearance of cell remnants from tissues $(3,4)$. This Research Topic bundles a set of manuscripts describing various ways of how such "uncleared" cell remnants participate in the pathogenesis of chronic inflammatory diseases and also cancer. Improving our knowledge of the immune modulatory language(s) spoken by dying and dead cells and their constituents may prove essential for understanding the key processes involved. Ultimately and hopefully, this may lead to the development of new classes of therapeutic and disease-modifying agents (5).

For example, González and Hidalgo emphasize that it is now possible to take advantage of the huge amount of published evidence on therapeutic modulation of the liver $\mathrm{X}$ receptor activity in clearance-associated diseases (6). Notably, pharmacological regulation of such nuclear factors, which are activated upon recognition of dying cells, may enhance the ability of macrophages to clear dead cells and thereby provide additional beneficial effects for treating clearance-related diseases like osteoporosis, rheumatoid arthritis, atherosclerosis, diabetes, and Alzheimer's disease (7-10).

Upon recruitment to sites of acute inflammation, neutrophils respond either with phagocytosis of the inflammatory trigger, degranulation, or with the formation of neutrophil-extracellulartraps (NETs) (11) exposing modified chromatin at the site of the initial injury (12). The nature of this material implies the massive death of neutrophils, and this response is important for both the inactivation of the aggressor and the resolution of the initial inflammation (13). However, how this battlefield is finally cleaned up and cleared has not been studied yet and may surely provide new therapeutic options for autoimmune diseases (12, 14). Intense current research on the immunobiology of this special way of dying called NETosis also promises new therapeutic targets for ameliorating autoinflammation $(15,16)$. Severe and standard treatment resistant forms of pulmonary inflammation may also profit by novel dual interventions targeting both cell survival and promotion of apoptotic cell clearance by phagocytes as Felton et al. and Szondy et al. summarize in this issue $(17,18)$. Although one of the multiple mechanisms of action of glucocorticoids is to enhance apoptotic cell clearance by macrophages (19), their long-term use has many side effects that strongly burden chronically diseased patients leading to higher rates of morbidity. Alternatives to classic therapies and specific pathogenesis-targeted therapies are therefore very much welcome.

The many different signals expressed or secreted by apoptotic cells noticeably determine the reaction of the organism to the event triggering death. Any shortcomings in phagocytic clearance, either by impaired clearance, excessive death or any other reason, are invariably related to continuous stimulation of the organism by either pro-inflammatory/destructive or antiinflammatory/healing signaling. Many chronic inflammatory diseases are driven and somehow modulated by metabolites released from dying cells. For example, Chen et al. present an overview of the various sites of action of nucleotides in inflammatory conditions (20). Intervention at this level may shift the balance toward anti-inflammation, thereby achieving the therapeutic goal more effectively.

In the case of solid tumors, the metabolites and, especially, the danger signals released may serve as biomarkers. Gehrmann et al. nicely demonstrate in this Research Topic that stress response proteins are released already by premalignant conditions of the liver as well as by hepatocellular carcinoma (21). This can be important for prognosis, prediction, and monitoring. The tumor microenvironment, especially directly after anti-cancer treatment, is overflowing with mediators and signals from dead and dying cells. To obtain an efficient anti-tumor immune response, an immune-suppressive microenvironment has to be shifted to an activating one. The 
latter might be achieved by rendering the tumor cells immunogenic, namely, by inducing immunogenic tumor cell death forms by standard treatments such as radio- and/or chemotherapy (22). Furthermore, short range danger signals foster leukocyte infiltration into the tumor and initiate an inflammatory response, which is afterwards supplanted by long-range healing and regenerative signals, which then, in contrast, may support tumor proliferation. The review from Willems summarizes evidence documenting the dark side of apoptosis in modulating anti-tumor responses (23). A delicate balance exists between anti-tumor reactions and counteracting immune suppression. In this scenario, the role of tumor associated macrophages as sensors and central orchestrators of tumor-promoting reparatory and anti-inflammatory signals has recently been highlighted by Ford et al. (24). In addition, avoiding tumor repopulation after anti-cancer therapy by considering the immune-suppressive consequences of apoptotic cell clearance should be taken into account as a cautionary premise for each and every anti-cancer treatment (25-28). Of note, inflammatory reactions, DNA damage responses, and cell death forms are highly interconnected (29). Alterations in the clearance of dying and dead cells, their remnants, and their constituents that leak out after membrane rupture are therefore central elements in all inflammatory conditions, starting from its origin and ending in its resolution.

\section{REFERENCES}

1. Munoz LE, Lauber K, Schiller M, Manfredi AA, Herrmann M. The role of defective clearance of apoptotic cells in systemic autoimmunity. Nat Rev Rheumatol (2010) 6(5):280-9. doi:10.1038/nrrheum.2010.46

2. Kimani SG, Geng K, Kasikara C, Kumar S, Sriram G, Wu Y, et al. Contribution of defective PS recognition and efferocytosis to chronic inflammation and autoimmunity. Front Immunol (2014) 5:566. doi:10.3389/fimmu.2014.00566

3. Manfredi AA, Covino C, Rovere-Querini P, Maugeri N. Instructive influences of phagocytic clearance of dying cells on neutrophil extracellular trap generation. Clin Exp Immunol (2015) 179(1):24-9. doi:10.1111/cei.12320

4. Poon IK, Lucas CD, Rossi AG, Ravichandran KS. Apoptotic cell clearance: basic biology and therapeutic potential. Nat Rev Immunol (2014) 14(3):166-80. doi:10.1038/nri3607

5. Munoz LE, Herrmann M, Berens C. Dying autologous cells as instructors of the immune system. Clin Exp Immunol (2015) 179(1):1-4. doi:10.1111/cei.12478

6. Alonso-Gonzalez N, Hidalgo A. Nuclear receptors and clearance of apoptotic cells: stimulating the macrophage's appetite. Front Immunol (2014) 5:211. doi:10.3389/fimmu.2014.00211

7. Asquith DL, Miller AM, Hueber AJ, McKinnon HJ, Sattar N, Graham GJ, et al. Liver $\mathrm{X}$ receptor agonism promotes articular inflammation in murine collageninduced arthritis. Arthritis Rheum (2009) 60(9):2655-65. doi:10.1002/art.24717

8. Im SS, Osborne TF. Liver x receptors in atherosclerosis and inflammation. Circ Res (2011) 108(8):996-1001. doi:10.1161/CIRCRESAHA.110.226878

9. Koldamova RP, Lefterov IM, Staufenbiel M, Wolfe D, Huang S, Glorioso JC, et al. The liver X receptor ligand T0901317 decreases amyloid beta production in vitro and in a mouse model of Alzheimer's disease. J Biol Chem (2005) 280(6):4079-88. doi:10.1074/jbc.M411420200

10. Kleyer A, Scholtysek C, Bottesch E, Hillienhof U, Beyer C, Distler JH, et al. Liver X receptors orchestrate osteoblast/osteoclast crosstalk and counteract pathologic bone loss. J Bone Miner Res (2012) 27(12):2442-51. doi:10.1002/jbmr.1702

11. Brinkmann V,Zychlinsky A. Neutrophil extracellular traps: is immunity the second function of chromatin? J Cell Biol (2012) 198(5):773-83. doi:10.1083/jcb. 201203170

12. Pieterse E, Van Der Vlag J. Breaking immunological tolerance in systemic lupus erythematosus. Front Immunol (2014) 5:164. doi:10.3389/fimmu.2014.00164

13. Schauer C, Janko C, Munoz LE, Zhao Y, Kienhofer D, Frey B, et al. Aggregated neutrophil extracellular traps limit inflammation by degrading cytokines and chemokines. Nat Med (2014) 20(5):511-7. doi:10.1038/nm.3547
14. Radic M. Clearance of apoptotic bodies, NETs and biofilm DNA: implications for autoimmunity. Front Immunol (2014) 5:365. doi:10.3389/fimmu.2014.00365

15. Hakkim A, Fürnrohr BG, Amann K, Laube B, Abed UA, Brinkmann V, et al. Impairment of neutrophil extracellular trap degradation is associated with lupus nephritis. Proc Natl Acad Sci USA (2010) 107(21):9813-8. doi:10.1073/pnas. 0909927107

16. Kessenbrock K, Krumbholz M, Schonermarck U, Back W, Gross WL, Werb Z, et al. Netting neutrophils in autoimmune small-vessel vasculitis. Nat Med (2009) 15(6):623-5. doi:10.1038/nm.1959

17. Felton JM, Lucas CD, Rossi AG, Dransfield I. Eosinophils in the lung - modulating apoptosis and efferocytosis in airway inflammation. Front Immunol (2014) 5:302. doi:10.3389/fimmu.2014.00302

18. Szondy Z, Garabuczi É, Joós G, Tsay GJ, Sarang Z. Impaired clearance of apoptotic cells in chronic inflammatory diseases: therapeutic implications. Front Immunol (2014) 5:354. doi:10.3389/fimmu.2014.00354

19. Lauber K, Keppeler H, Munoz LE, Koppe U, Schroder K, Yamaguchi H, et al. Milk fat globule-EGF factor 8 mediates the enhancement of apoptotic cell clearance by glucocorticoids. Cell Death Differ (2013) 20(9):1230-40. doi:10.1038/cdd.2013.82

20. Chen J, Zhao Y, Liu Y. The role of nucleotides and purinergic signaling in apoptotic cell clearance - implications for chronic inflammatory diseases. Front Immunol (2014) 5:656. doi:10.3389/fimmu.2014.00656

21. Gehrmann M, Cervello M, Montalto G, Cappello F, Gulino A, Knape C, et al. Heat shock protein 70 (Hsp70) serum levels differ significantly in patients with chronic hepatitis, liver cirrhosis, and hepatocellular carcinoma. Front Immunol (2014) 5:307. doi:10.3389/fimmu.2014.00307

22. Frey B, Rubner Y, Kulzer L, Werthmöller N, Weiss EM, Fietkau R, et al. Antitumor immune responses induced by ionizing irradiation and further immune stimulation. Cancer Immunol Immunother (2014) 63(1):29-36. doi:10.1007/s00262013-1474-y

23. Willems JJLP, Arnold BP, Gregory CD. Sinister self-sacrifice: the contribution of apoptosis to malignancy. Front Immunol (2014) 5:299. doi:10.3389/fimmu. 2014.00299

24. Ford CA, Petrova S, Pound JD, Voss JJ, Melville L, Paterson M, et al. Oncogenic properties of apoptotic tumor cells in aggressive B cell lymphoma. Curr Biol (2015) 25(5):577-88. doi:10.1016/j.cub.2014.12.059

25. Huang Q, Li F, Liu X, Li W, Shi W, Liu FF, et al. Caspase 3-mediated stimulation of tumor cell repopulation during cancer radiotherapy. Nat Med (2011) 17(7):860-6. doi:10.1038/nm.2385

26. Lauber K, Munoz LE, Berens C, Jendrossek V, Belka C, Herrmann M. Apoptosis induction and tumor cell repopulation: the yin and yang of radiotherapy. Radiat Oncol (2011) 6:176. doi:10.1186/1748-717X-6-176

27. Lauber K, Ernst A, Orth M, Herrmann M, Belka C. Dying cell clearance and its impact on the outcome of tumor radiotherapy. Front Oncol (2012) 2:116. doi: $10.3389 /$ fonc. 2012.00116

28. Lauber K, Herrmann M. Tumor biology: with a little help from my dying friends. Curr Biol (2015) 25(5):R198-201. doi:10.1016/j.cub.2015.01.040

29. Gaipl US, Multhoff G, Scheithauer H, Lauber K, Hehlgans S, Frey B, et al. Kill and spread the word: stimulation of antitumor immune responses in the context of radiotherapy. Immunotherapy (2014) 6(5):597-610. doi:10.2217/imt.14.38

Conflict of Interest Statement: The authors declare that the research was conducted in the absence of any commercial or financial relationships that could be construed as a potential conflict of interest.

Received: 09 March 2015; accepted: 13 March 2015; published online: 25 March 2015. Citation: Muñoz LE, Berens C, Lauber K, Gaipl US and Herrmann M (2015) Apoptotic cell clearance and its role in the origin and resolution of chronic inflammation. Front. Immunol. 6:139. doi: 10.3389/fimmu.2015.00139

This article was submitted to Inflammation, a section of the journal Frontiers in Immunology.

Copyright (C) 2015 Muñoz, Berens, Lauber, Gaipl and Herrmann. This is an openaccess article distributed under the terms of the Creative Commons Attribution License (CC BY). The use, distribution or reproduction in other forums is permitted, provided the original author(s) or licensor are credited and that the original publication in this journal is cited, in accordance with accepted academic practice. No use, distribution or reproduction is permitted which does not comply with these terms. 